\title{
Prevalence of vertebral fractures in women and men in the population-based Tromsø Study
}

Svanhild Waterloo ${ }^{*}$, Luai A Ahmed ${ }^{2}$, Jacqueline R Center ${ }^{3}$, John A Eisman³ ${ }^{3}$ Bente Morseth', Nguyen D Nguyen³, Tuan Nguyen ${ }^{3}$, Anne J Sogaard ${ }^{4}$ and Nina Emaus ${ }^{2}$

\begin{abstract}
Background: Osteoporotic vertebral fractures are, as the hip fractures, associated with increased morbidity and mortality. Norway has one of the highest reported incidences of hip fractures in the world. Because of methodological challenges, vertebral fractures are not extensively studied. The aim of this population based study was to describe, for the first time, the age- and sex specific occurrence of osteoporotic vertebral fractures in Norway.

Methods: Data was collected in the Tromso Study, 2007/8 survey. By the use of dual x-ray absorptiometry (GE Lunar Prodigy) vertebral fracture assessments were performed in 2887 women and men aged from 38 to 87 years, in addition to measurements of bone mineral density at the femoral sites. Information on lifestyle was collected through questionnaires. Comparisons between fractures and non-fractures were done sex stratified, by univariate analyses, adjusting for age when relevant.

Results: The prevalence of vertebral fractures varied from about 3\% in the age group below 60 to about 19\% in the $70+$ group in women, and from $7.5 \%$ to about $20 \%$ in men, with an overall prevalence of $11.8 \%$ in women and $13.8 \%$ in men $(p=0.07)$. Among those with fractures, only one fracture was the most common; two and more fractures were present in approximately $30 \%$ of the cases. Fractures were seen from the fourth lumbar to the fifth thoracic vertebrae, most common between first lumbar and sixth thoracic vertebrae. The most common type of fracture was the wedge type in both sexes. Bone mineral density at the hip differed significantly according to type of fracture, being highest in those with wedge fractures and lowest in those with compression fractures.
\end{abstract}

Conclusions: The prevalence of vertebral fractures increased by age in women and men, but the overall prevalence was lower than expected, considering the high prevalence of hip and forearm fractures in Norway. In both sexes, the wedge type was the fracture type most frequently observed and most common in the thoracic region.

Keywords: Morphometry, Vertebral deformity, Vertebral fractures, Population-based study

\section{Background}

Osteoporosis and osteoporotic fractures occur so commonly worldwide, they are a serious health issue $[1,2]$. Forearm, vertebral and hip fractures are reportedly the most frequent osteoporotic fractures [3]. Whereas hip fractures are the most costly because of the expenses for treatment and rehabilitation imposed on society [4], many publications indicate that vertebral fractures are

\footnotetext{
* Correspondence: svanhild.h.waterloo@uit.no

'Department of Community Medicine, Faculty of Health Sciences, University of Tromsø, 9037 Tromsø, Norway

Full list of author information is available at the end of the article
}

the most common form of osteoporotic fractures [5-7]. However, limited data support this claim. Some studies report that only one in three vertebral fractures are diagnosed $[6,8]$ and as such argue that vertebral fractures are largely under diagnosed [9-11].

Osteoporotic vertebral fractures-meaning fractures in one or more vertebrae-are, as the hip fractures, associated with increased morbidity [12] and mortality [13-15]. Having one vertebral fracture also significantly increases the risk of experiencing subsequent vertebral fractures [16-18], as well as other fractures [9,19-21]. In general, we have less knowledge about vertebral

\section{Ciomed Central}


fractures than about other fractures because of the methodological problems related to their verification. Prevalence data from population based studies indicate a substantial variation in overall prevalence ranging from $10 \%$ to $25 \%$ in women and from $10 \%$ to $27 \%$ in men $[4,5,17,22-30]$. Prevalence data from patient studies [31-34] are not suited to define prevalence in a general population, because the health states associated with "patient" status may affect the risk and frequency of fractures. Several studies report that Norway is among the countries in the world with the highest rate of osteoporotic fractures, including hip [35] and forearm [36]. Until now, prevalence data on vertebral fractures have not been presented from any major population based study in Norway. Thus, knowledge and data on the frequency of vertebral fractures in a country with reported high rates of other osteoporotic fractures is warranted.

Data presented here are generated in the population based Tromsø Study (2007/08 survey). The aims of the study are to describe the age related rate of vertebral fractures in men and women and to examine which type of fracture is the most common, which vertebrae are the most prone to fractures, as well as the severity of these fractures.

\section{Methods}

\section{Study population}

The Tromsø Study is a longitudinal population based multi-purposed study focusing on lifestyle related diseases, comprising six repeated surveys and examinations starting in 1974 (Tromsø I) and repeated in 1979/80, 1986/87, 1994/95, 2001/02 and 2007/08 (Tromsø VI) [37]. Only men were invited to the first survey which focused on cardiovascular diseases, but from Tromsø II $1979 / 80$ both women and men have been included. The participation rate has ranged from $65 \%$ to $77 \%$ [38]. Each survey has been conducted in two phases, with the most basic examination in phase 1 (height, weight, BP, blood samples, and questionnaires) and more extensive examinations for a random sub-sample of the cohort in phase 2, depending on available resources.

For Troms $ø$ VI, in total 19762 subjects were invited and 12984 (65.7\%) attended phase 1, 6054 men (62.9\%) and 6930 women $(68.4 \%)$. Among those participating in phase 1, a total of 11484 subjects were invited for phase 2, and 7307 (64\%) attended, 3141 men (61.5\%) and 4166 women $(65.3 \%)$. Among those attending phase 2 , only persons with valid bone mineral density (BMD) measurement from Tromsø V in 2001/2002 were invited for a Dual X-ray (DXA) BMD measurement of the hip, i.e. a dual femur scan, and altogether 3854 persons attended. Among these, a lateral vertebral assessment (LVA), hereafter called vertebral fracture assessment
(VFA) was performed in a randomly selected group of 2894 persons (Figure 1). Seven blurred VFA scans had to be excluded, leaving 2887 persons, 1681 women and 1206 men, with clearly measurable VFA scans and total hip measurements.

\section{Measurements}

Vertebral morphometry is a quantitative method developed for identification of osteoporotic vertebral fractures based on the measurement of vertebral heights. Although spine radiographs are generally considered to be the gold standard for the diagnosis of vertebral fractures [20,39], the morphometric method is recognized for being easy, precise and using low radiation exposure [40-42]. When combined with BMD measurements, it is even argued it could become the "gold standard" [43]. Determination of fracture types was done visually according to a standard set by GE Lunar Prodigy, also shown in Kim et al. [11]. Three types of fractures are identified: wedge, biconcave, and compression, according to three degrees of severity, ranging from mild through moderate to severe [40]. The wedge fractures are characterized by deformed structure of the anterior part of the vertebrae, the biconcave of the middle part, and the compression of the total vertebrae. All our scans were taken according to a standard set by GE Lunar Prodigy, Lunar Corp., Madison, USA, and in GE Lunar encore version 12.20. Daily phantom measurements were performed throughout the survey. Specially trained technicians did the scanning according to the standardized protocol, and one of them performed the quality assessment of the total material afterwards. In a recent validation study, the short term in vivo precision error for the Lunar Prodigy was $1.7 \%$ and $1.2 \%$ for the femoral neck and total hip measurements, respectively [44]. For precision analysis of the VFA, random sample of 50 participants was reanalyzed. The mean intra-class correlation coefficient was $0.82,0.79,0.82$, and 0.84 for anterior, middle, posterior, and average height, respectively, all vertebrae considered. At the vertebrae with highest frequency of present deformity, exemplified by $7^{\text {th }}$ and $12^{\text {th }}$ thoracic vertebrae, the intra-class correlation coefficient varied between 0.77 and 0.92 , with a mean of 0.86. Additional measurements taken were dual hip BMD expressed as $\mathrm{g} / \mathrm{cm}^{2}$, and height and weight, in light clothing without shoes, were measured in all the participants.

\section{Questionnaire}

Information on lifestyle variables was collected through questionnaires in both phases of the study. The question on smoking had three alternatives: present, former, and never. These were grouped into two, where former and never smokers were categorized as "not smoking" and 


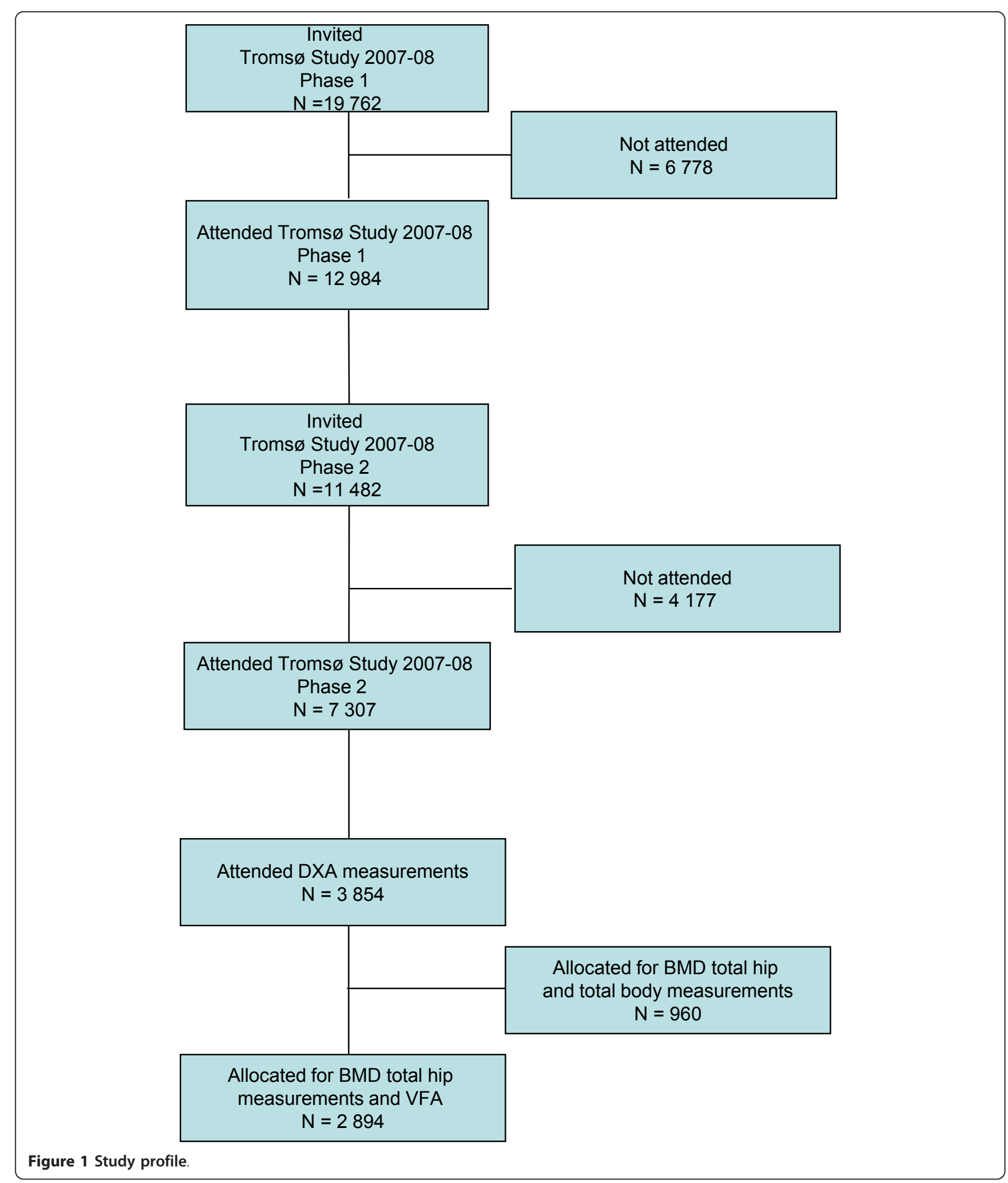

smokers as "smoking". The question on physical activity had four alternatives, from sedentary through moderate and high to very high physical activity level each week. Having few answers both in the "sedentary" and "very high physical activity level" groups, we categorized sedentary and moderate physical activity level as moderate, and high/very high level as high. Five levels of selfperceived health (very good, good, neither nor, bad, very 
Table 1 Descriptive statistics by gender and morphometric vertebral fracture, the Tromsø Study 200708

\begin{tabular}{|c|c|c|c|}
\hline Gender and factor & $\begin{array}{c}\text { No } \\
\text { Fracture }\end{array}$ & $\begin{array}{l}\text { Vertebral } \\
\text { fracture }\end{array}$ & $\begin{array}{c}P- \\
\text { value }\end{array}$ \\
\hline Men $(\mathrm{N})$ & 1040 & 166 & \\
\hline$\overline{\text { Age }}$ & $64.8(9.3)$ & $69.0(9.2)$ & $\begin{array}{c}< \\
0.0001\end{array}$ \\
\hline Weight, kg & $84.5(12.3)$ & $82.8(11.5)$ & 0.078 \\
\hline Height, cm & $175.5(6.5)$ & $174.4(6.7)$ & 0.062 \\
\hline $\mathrm{BMI}, \mathrm{kg} / \mathrm{m}^{2}$ & $27.4(3.5)$ & $27.2(3.4)$ & 0.457 \\
\hline $\begin{array}{l}\text { Bone mineral density, total hip } \\
\left(\mathrm{g} / \mathrm{cm}^{2}\right)\end{array}$ & $\begin{array}{l}1.03(0.14) \\
n=1007\end{array}$ & $\begin{array}{l}0.97(0.15) \\
n=160\end{array}$ & $\begin{array}{c}< \\
0.0001\end{array}$ \\
\hline Education & & & 0.147 \\
\hline $1(n ; \%)$ & $324(31.9)$ & $54(33.5)$ & \\
\hline 2 & $287(28.2)$ & $55(34.2)$ & \\
\hline 3 & $405(39.9)$ & $52(32.3)$ & \\
\hline Physical activity & & & 0.577 \\
\hline High active $(n ; \%)$ & $213(22.6)$ & $31(20.5)$ & \\
\hline Low active & $731(77.4)$ & $120(79.5)$ & \\
\hline Smoking status & & & 0.988 \\
\hline Daily smokers (n; \%) & $159(15.5)$ & $25(15.5)$ & \\
\hline Non smoking & $868(84.5)$ & $136(84.5)$ & \\
\hline Health status & & & 0.574 \\
\hline Good (n; \%) & $662(64.1)$ & $102(61.8)$ & \\
\hline Poor & $371(35.9)$ & $63(38.2)$ & \\
\hline Women $(\mathrm{N})$ & 1482 & 199 & \\
\hline Age & $64.7(9.3)$ & 70.5 (8.6) & $\begin{array}{c}< \\
0.0001\end{array}$ \\
\hline Weight, kg & $71.1(12.5)$ & $68.4(12.7)$ & 0.005 \\
\hline Height, cm & $162.5(6.3)$ & $160.4(7.1)$ & $\begin{array}{c}< \\
0.0001\end{array}$ \\
\hline $\mathrm{BMl}, \mathrm{kg} / \mathrm{m}^{2}$ & $26.9(4.6)$ & $26.6(4.5)$ & 0.297 \\
\hline $\begin{array}{l}\text { Bone mineral density, total hip } \\
\left(\mathrm{g} / \mathrm{cm}^{2}\right)\end{array}$ & $\begin{array}{l}0.91(0.13) \\
N=1392\end{array}$ & $\begin{array}{c}0.83(0.11) \\
\mathrm{n}=179\end{array}$ & $\begin{array}{c}< \\
0.0001\end{array}$ \\
\hline Education & & & 0.009 \\
\hline 1 (primary school) (n; \%) & $627(43.0)$ & $106(54.4)$ & \\
\hline 2 (O-level) & $375(25.7)$ & $44(22.6)$ & \\
\hline 3 (more than O-level) & $456(31.3)$ & $45(23.1)$ & \\
\hline Physical activity & & & 0.796 \\
\hline High active $(n ; \%)$ & $144(11.2)$ & $18(10.5)$ & \\
\hline Low active & $\begin{array}{l}1143 \\
(88.8)\end{array}$ & $153(89.5)$ & \\
\hline Smoking status & & & 0.750 \\
\hline Daily smokers (n; \%) & $265(18)$ & $37(19)$ & \\
\hline Non smoking & $1189(82)$ & $156(81)$ & \\
\hline Health status & & & 0.029 \\
\hline Good (n; \%) & $905(61.9)$ & $106(53.8)$ & \\
\hline Poor & $557(38.1)$ & $91(46.2)$ & \\
\hline
\end{tabular}

*P-values refer to univariate analyses

bad) were categorized into two, good (very good and good) and poor. Educational information was combined from five to three levels: primary school only (i.e. 7 years), O-level, and more than O-level. Our study population being rather old, primary school only was not uncommon (Table 1).

\section{Statistics}

Baseline characteristics in women and men with and without fractures were compared by univariate analyses, using Independent sample $\mathrm{T}$-test for continuous variables and chi-square testing for categorical variables. To adjust for age differences, logistic regression was applied to test the differences of the significant variables between the groups. Prevalence of morphometric fractures in women and men was compared by chi square testing, and so was distribution of deformities and types of deformities (wedge, biconcave, or compression). The mean BMD difference between the three different types of deformities was tested in both sexes using ANOVA, adjusting for age. The statistical analyses were performed by SPSS version 18, and a $p$-value below 0.05 was considered significant.

The Regional Committee of Research Ethics recommended the study, and written informed consent was obtained from all participants.

\section{Results}

The study cohort comprises 2887 women and men ranging from 38 to 87 years of age (Table 1). Vertebral deformities were present in 199 women and 166 men. Women with vertebral fractures were older, shorter, weighted less, had lower total hip BMD, lower educational level, and lower self-reported health compared to those without fractures. When adjusting for age, only weight and BMD were significantly different between the groups. Men with vertebral fractures were older and had lower BMD compared to those without fractures. Adjusting for age, BMD remained significantly different between the groups (Table 1). With an overall prevalence of any deformity of $11.8 \%$ in women and $13.8 \%$ in men, the prevalence was not significantly different between the sexes $(p=0.07)$ (Table 2$)$. In both sexes, the prevalence increased significantly by age, in women

Table 2 Prevalence of morphometric vertebral fracture by age in women and men

\begin{tabular}{lcccc}
\hline $\begin{array}{l}\text { Vertebral } \\
\text { fracture }\end{array}$ & $\begin{array}{c}\text { Fracture/ } \\
\mathbf{N}\end{array}$ & $\begin{array}{c}\text { Prevalence } \\
(\%)\end{array}$ & $\begin{array}{c}\text { Fracture/ } \\
\mathbf{N}\end{array}$ & $\begin{array}{c}\text { Prevalence } \\
\text { (\%) }\end{array}$ \\
\hline $\begin{array}{l}\text { Any fracture } \\
95 \% \mathrm{Cl}\end{array}$ & $166 / 1206$ & 13.8 & $199 / 1681$ & 11.8 \\
\hline Age group & & $(11.9,15.8)$ & & $(10.4,13.5)$ \\
\hline$<60$ & $26 / 342$ & 7.6 & $14 / 412$ & 3.4 \\
$60-69$ & $50 / 420$ & 11.9 & $80 / 721$ & 11.1 \\
$70+$ & $90 / 444$ & 20.3 & $105 / 548$ & 19.2 \\
\hline
\end{tabular}


from $3.4 \%$ below the age of 60 to $19.2 \%$ over 70 years, in men from $7.6 \%$ to $20.3 \%$, respectively (Table 2 ). The prevalence was not significantly different between the sexes in the age groups 60-69 years $(p=0.37), 70+$ years $(p=0.36)$, but was higher in men in the age group below 60 years $(p=0.008)$.

Numbers of deformities varied from 1 to 6 in each person so that in total there were 317 and 234 deformities in women and men, respectively. The distribution of numbers of deformities, categorized into $0,1,2,3$ or more deformities, was not significantly different between the sexes $(p=0.169)$ (Table 3$)$. In both sexes, more than $95 \%$ of the deformities were either moderate or severe wedge, moderate or severe biconcave or moderate compression (Table 4). Types of deformities differed significantly between the sexes $(p=0.025)$. In women, half $(51 \%)$ of the deformities were wedges (moderate or severe), more than one third (37\%) were biconcavities (mild, moderate, or severe), and $12 \%$ were compressions (moderate or severe). In men, the proportions with the last two fracture types were somewhat lower $(33 \%$ and $6 \%)$, whereas the proportions with wedge deformities were higher $(60 \%)$ than in women (Table 4$)$. The distribution of the locations of the deformities showed a similar pattern in men and women (Figure 2). In women, the majority of deformities, defined as more than $10 \%$ of the total deformities, were at $7^{\text {th }}, 9^{\text {th }}, 12^{\text {th }}$ thoracic and $1^{\text {st }}$ lumbar vertebrae, in men at $7^{\text {th }}, 8^{\text {th }}, 12^{\text {th }}$ thoracic, and $1^{\text {st }}$ lumbar vertebrae (Figure $3 \mathrm{~A}$ and $3 \mathrm{~B}$ ). In both sexes, most of the wedge deformities were present from $12^{\text {th }}$ thoracic and above, and most of the biconcave deformities were from $12^{\text {th }}$ thoracic and below, in women also from the $11^{\text {th }}$ thoracic (Figure $3 \mathrm{~A}$ and $3 \mathrm{~B}$ ).

Finally, we examined the association between types of deformities and BMD at the total hip. In both sexes, BMD was significantly lower in persons with deformities compared to those without $(p<0.001)$. BMD also differed significantly according to type of deformity (ANOVA: $p=0.02$ in women, $p=0.04$ in men). In those with only one type of deformity observed, the ageadjusted mean total hip BMD was $0.855,0.801$ and $0.802 \mathrm{~g} / \mathrm{cm}^{2}$ in women, and $0.998,0.950$ and 0.935 in

Table 3 Distribution of numbers of deformities in women and men

\begin{tabular}{|c|c|c|c|c|}
\hline \multirow[b]{2}{*}{$\begin{array}{l}\text { Numbers of } \\
\text { deformities }\end{array}$} & \multicolumn{2}{|c|}{ Men $(N=1206)$} & \multicolumn{2}{|c|}{ Women $(\mathrm{N}=1681)$} \\
\hline & $\%(N)$ & $\begin{array}{c}95 \% \mathrm{Cl} \\
(\%)\end{array}$ & $\%(\mathrm{~N})$ & $\begin{array}{c}95 \% \mathrm{Cl} \\
(\%)\end{array}$ \\
\hline At least 1 deformity & $9.7(117)$ & $8.0,11$ & $7.8(131)$ & $46.5,9.1$ \\
\hline 2 deformities & $3.0(36)$ & $2.0,4.0$ & $2.5(42)$ & $1.8,3.2$ \\
\hline 3 deformities or more & $1.0(13)$ & $0.4,1.6$ & $1.4(26)$ & $0.8,2.0$ \\
\hline All & $\begin{array}{c}13.8 \\
(166)\end{array}$ & $11.9,15.8$ & $\begin{array}{c}11.8 \\
(199)\end{array}$ & $10.4,13.5$ \\
\hline
\end{tabular}

Table 4 Types of deformities at any vertebral level in 1681 women and 1206 men

\begin{tabular}{|c|c|c|}
\hline & Men & Women \\
\hline Types of deformities & N (\%) & N (\%) \\
\hline Wedge & $141(60.2)$ & $162(51)$ \\
\hline Mild wedge & $0(0)$ & $0(0)$ \\
\hline Moderate wedge & $92(39)$ & $86(27)$ \\
\hline Severe wedge & $49(21)$ & $76(24)$ \\
\hline Biconcave & $78(33.4)$ & $116(37)$ \\
\hline Mild biconcave & $0(0)$ & $7(2)$ \\
\hline Moderate biconcave & $49(21)$ & $62(19.5)$ \\
\hline Severe biconcave & $29(12.5)$ & $47(15)$ \\
\hline Compression & $15(6.4)$ & $39(12)$ \\
\hline Mild compression & $0(0)$ & $0(0)$ \\
\hline Moderate compression & $13(5.5)$ & $30(9.5)$ \\
\hline Severe compression & $2(1)$ & $9(3)$ \\
\hline
\end{tabular}

*Types of deformities differed significantly between the sexes $(p=0.025)$

men, with wedge, biconcave and compression deformities, respectively.

\section{Discussion}

The main finding in this study is that age was a significant predictor of vertebral deformities in both women and men with a prevalence increasing from approximately $3 \%$ in the age group below 60 years to approximately $20 \%$ in the age group $70+$ in women, and from approximately $7.5 \%$ to $20 \%$ in men, respectively.

The rates of hip and forearm fractures in Norway are among the highest in the world. Because of this, one would expect the occurrence of vertebral fractures to be high as well. A surprising finding from this study is that this is not the case. For women, it can even be regarded as rather low compared to other studies $[25,43]$, reported from Vietnam to be from $17.1 \%$ in the age group $50-59$ to $39.2 \%$ in the age group $70+$ (overall prevalence 23\%) and in Spain from $7.2 \%$ in the age group $55-59$ and $46.3 \%$ in the age group $75+$ (overall 21.4\%). In men, our results are more similar to those reported by others $[24,26]$, prevalence being $4.7 \%$ in the age group $60-69,10 \%$ in the $70-79$ group, $14.6 \%$ in the $80+$ group in Australia, and among Mexican men, 2\% in age group $50-59$ rising to $21.4 \%$ in the $80+$ group, with an overall prevalence score of 9.7\%. A multinational, European study from 1996 [45] found the overall prevalence to be $12 \%$ both in women and men, which is very much the same as in our study, but the Norwegian rates reported in that study were $19.2 \%$ in women, $15.7 \%$ in men, along with Sweden the highest rates in Europe. These Norwegian data were, however, extracted from a small sample (289 men, 298 women), mean age 65 years. In addition, another technology was used, making comparison difficult. 


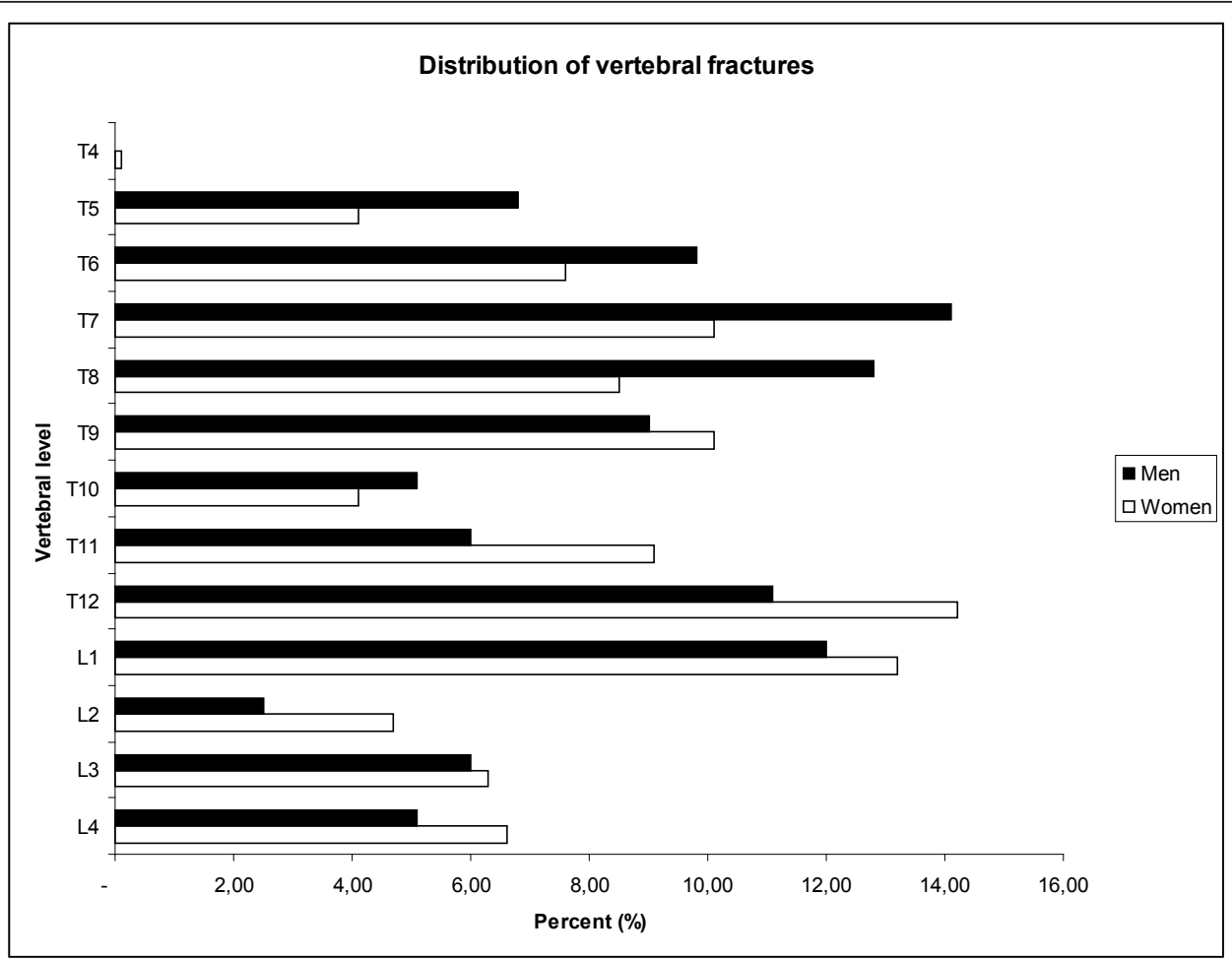

Figure 2 Percentage distribution of vertebral deformities (all types) according to vertebral level in 1681 women (317 deformities) and 1206 men (234 deformities). Calculations based on the following number of measurements: T4 = 2350, T5 = 2743, T6 = 2845, T7 = 2863, T8 = $2875, \mathrm{~T} 9=2878, \mathrm{~T} 10=2885, \mathrm{~T} 11-\mathrm{L} 3=2887, \mathrm{~L} 4=2848$.

As reported by others, we also find the prevalence of vertebral deformities to be highest in the midthoracic region $\left(5^{\text {th }}-9^{\text {th }}\right.$ thoracic) and thoracolumbar transition [42]. Wedge deformities were mostly found in the higher thoracic and the biconcave in the lower thoracic and lumbar region. It has been reported that fracture related disability may be greater among patient with lumbar fractures [42]. This could not be verified in the present study, but biconcave deformities were associated with lower BMD at the femoral sites in both sexes compared to the wedge deformities, suggesting a higher degree of severity. However, there is no consensus in the literature concerning type of vertebral fracture and severity [9]. The finding that prevalent radiographic vertebral fractures, of any type, are associated with low BMD measured at the femoral sites is reported by others [42]. As no X-rays were available in our study, we were unfortunately unable to assess whether the observed vertebral deformities are related to osteoporosis or other causes.

The Tromsø Study is a population-based, longitudinal study with a high participation rate. The present study is a cross-sectional survey within the framework of the Tromsø Study, where vertebral fracture assessments (VFA) were done for the first time. The intra-class correlation coefficient showed good reproducibility, indicating high methodological precision. Limitations of this study are that only prevalence data on vertebral deformities are presently available, also vertebral deformities were identified by DXA scanning only. Quality control of our data with $\mathrm{x}$-rays on a sub-group was not possible within the scope of the survey. It is, however, reported that DXA scans are more precise in measuring moderate and severe than mild deformities [20]. Because of the methodological uncertainty concerning detection of mild deformities, the prevalence reported from our study may therefore be under-estimations. To address the issue of selection bias, we compared central characteristics between women and men who were randomly selected to either total body (TB) measurements (960 persons) or to the VFA (2894). In the VFA group, $58 \%$ were female compared to $62 \%$ in the TB group, with an OR of 1.21 (95\% CI 1.04, 1.41), adjusted for age 1.22 (95\% CI 1.05, 1.42). In the VFA group, both women and men were younger (65.4 versus 67.5 years in women, 65.3 versus 68.6 years in men), taller (162.2 versus $161.2 \mathrm{~cm}$ in women, 175.3 versus 174.4 $\mathrm{cm}$ in men), and men in the VFA group were also heavier (84.3 versus $82.3 \mathrm{~kg}$ ) compared to men in the TB group. BMD levels at the total hip and femoral neck, health status, educational level and physical activity level did not differ between the groups. Despite the random selection, the VFA group was younger with a slightly higher 

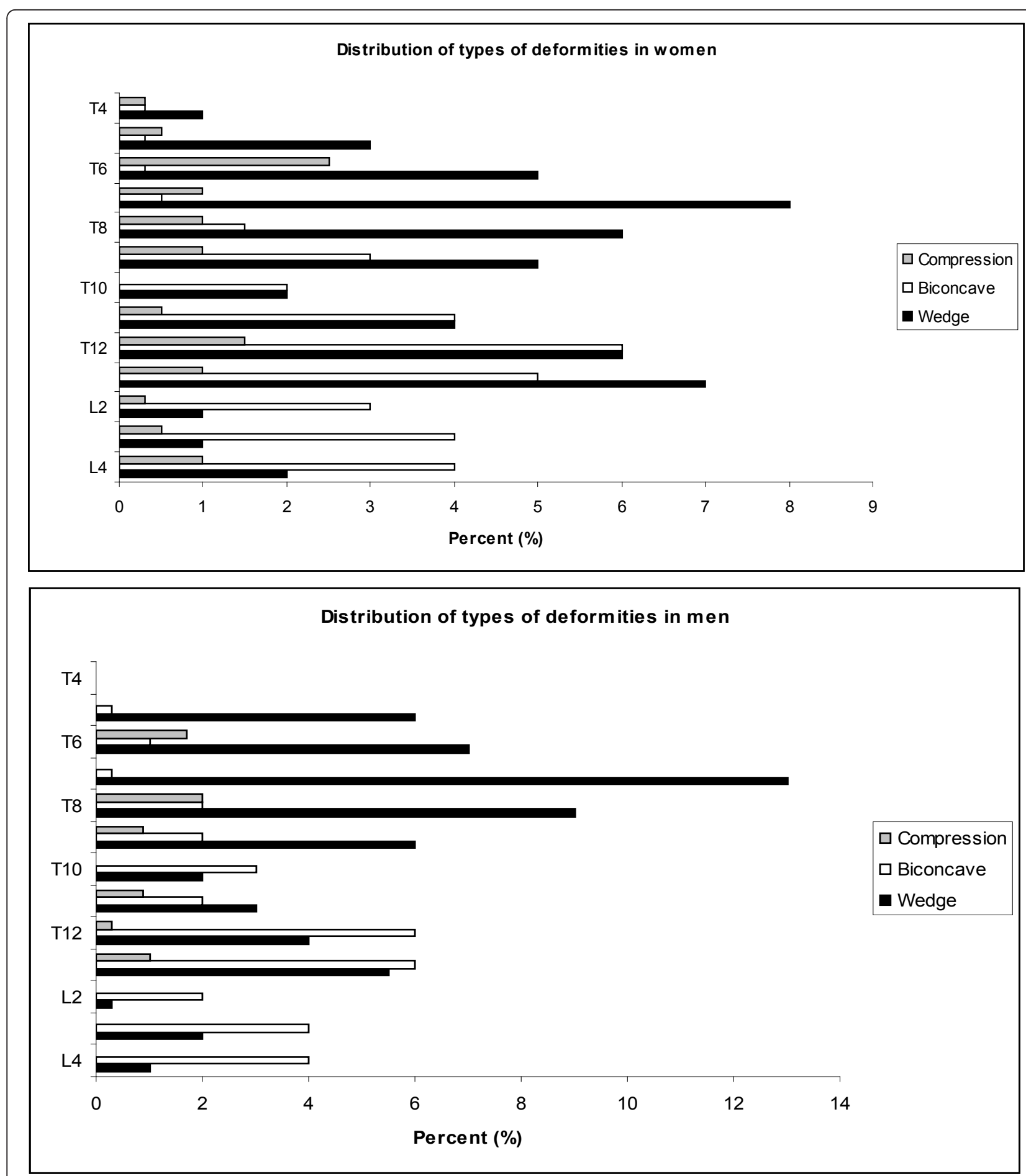

Figure 3 Distribution of types of vertebral deformities according to vertebral level in A. 1681 women and B. 1206 men.

proportion of women. However, when we compare the VFA group with the remaining phase 2 participants of the Troms $\varnothing$ VI survey, whom to our best knowledge should be a representative sample [37], the VFA sample of women and men was slightly older (3 years) and shorter $(2 \mathrm{~cm})$, but did not differ significantly in any other way. To summarize: we believe that the representativity of our sample is fair.

Throughout the study, we have deliberately used the term "vertebral deformity", though regarding these 
deformities as vertebral fractures $[12,46]$. Interestingly, the prevalence of vertebral fractures in the Tromsø population, which is considered a representative Norwegian population [38], does not follow the trend reported for non-vertebral fractures [35,36]. Difference in fracture mechanisms may possibly explain the discrepancy in prevalence, as non-vertebral fractures are connected to falls $[47,48]$, whereas vertebral fractures are not [5]. One possible interpretation of the findings from this study is that the prevalence of vertebral fractures was low because our population was generally healthy and because of possible underestimations of mild deformities with the technology used. It has been reported that a large amount of vertebral fractures are asymptomatic [11]. Further studies should elaborate if physical function, pain and self-perceived health, as well as comorbidities, differ between persons with and without vertebral fractures.

\section{Conclusions}

Although Norway reportedly has one of the highest incidences of forearm and hip fractures in world, data from the population-based Tromsø Study indicate that the prevalence of vertebral fractures, which increases by increasing age, is not higher than reported from other populations. The wedge fractures which most frequently occur in the thoracic region are the most common in both sexes. BMD was significantly lower in persons with vertebral fractures compared to those without.

\section{Acknowledgements \\ The project was funded by grants from the Northern Norwegian Health Authorities. We are greatly thankful for the support provided by the Troms $\varnothing$ Study organization.}

\section{Author details}

${ }^{1}$ Department of Community Medicine, Faculty of Health Sciences, University of Tromsø, 9037 Tromsø, Norway. ${ }^{2}$ Department of Health and Care Sciences, Faculty of Health Sciences, University of Tromsø, 9037 Tromsø, Norway. ${ }^{3}$ Garvan Institute of Medical Research, University of New South Wales, Sydney, Australia. ${ }^{4}$ National Public Health Institute, Oslo, Norway.

\section{Authors' contributions}

Contributions of the authors to the manuscript included Study Concept and design: NE, SW, AJS; Aquistion of data: NE; SW, NDN, LAA; Analysis and interpretation of data: SW, NE, LAA, AJS, JC, JAE; Statistical analyses: SW, NE, TN; Critical revision of the manuscript: SW, LAA, AJS, BM, JC, NDN, TN, JAE, NE. All authors read and approved the final manuscript.

\section{Competing interests}

The authors declare that they have no competing interests with regard to this work.

Received: 9 September 2011 Accepted: 17 January 2012

Published: 17 January 2012

\section{References}

1. Compston J: Osteoporosis: social and economic impact. Radiol Clin North Am 2010, 48(3):477-482.
2. Bliuc D, Nguyen ND, Milch VE, Nguyen TV, Eisman JA, Center JR: Mortality risk associated with low-trauma osteoporotic fracture and subsequent fracture in men and women. JAMA 2009, 301(5):513-521.

3. Harvey N, Dennison E, Cooper C: Osteoporosis: impact on health and economics. Nat Rev Rheumatol 2010, 6(2):99-105.

4. Johnell O, Kanis J: An estimate of the worldwide prevalence and disability associated with osteoporotic fractures. Osteoporos Int 2006, 17(12):1726-1733.

5. Tsai KS, Twu SJ, Chieng PU, Yang RS, Lee TK, the Geriatric Study Group ROC: Prevalence of vertebral fractures in Chinese men and women in urban Taiwanese communities. Calcif Tissue Int 1996, 59(4):249-253.

6. Francis R, Aspray T, Hide G, Sutcliffe A, Wilkinson P: Back pain in osteoporotic vertebral fractures. Osteoporos Int 2008, 19(7):895-903.

7. Chen P, Krege JH, Adachi JD, Prior JC, Tenenhouse A, Brown JP, Papadimitropoulos E, Kreiger N, Olszynski WP, Josse RG, et al: Vertebral fracture status and the World Health Organization risk factors for predicting osteoporotic fracture risk. J Bone Miner Res 2009, 24(3):495-502.

8. Cooper C: Epidemiology and public health impact of osteoporosis. Baillieres Clin Rheumatol 1993, 7(3):459-477.

9. Roux C, Fechtenbaum J, Kolta S, Briot K, Girard M: Mild prevalent and incident vertebral fractures are risk factors for new fractures. Osteoporos Int 2007, 18(12):1617-1624.

10. Silverman S: Quality-of-life issues in osteoporosis. Curr Rheumatol Rep 2005, 7(1):39-45

11. Kim N, Rowe BH, Raymond G, Jen H, Colman I, Jackson SA, Siminoski KG, Chahal AM, Folk D, Majumdar SR: Underreporting of vertebral fractures on routine chest radiography. Am J Roentgenol 2004, 182(2):297-300.

12. Kanis JA, Johnell O, Oden A, Borgstrom F, Zethraeus N, Laet C, Jonsson B: The risk and burden of vertebral fractures in Sweden. Osteoporos Int 2004, 15(1):20-26.

13. Center JR, Nguyen TV, Schneider D, Sambrook PN, Eisman JA: Mortality after all major types of osteoporotic fracture in men and women: an observational study. The Lancet 1999, 353(9156):878-882.

14. lacovino J: Mortality outcomes after osteoporotic fractures in men and women. J Insur Med 2001, 33(4):316-320.

15. Johnell O, Kanis JA, Odén A, Sernbo I, Redlund-Johnell I, Petterson C, Laet C, Jönsson B: Mortality after osteoporotic fractures. Osteoporos Int 2004, 15(1):38-42.

16. Lindsay R, Silverman SL, Cooper C, Hanley DA, Barton I, Broy SB, Licata A, Benhamou L, Geusens P, Flowers K, et al: Risk of new vertebral fracture in the year following a fracture. JAMA 2001, 285(3):320-323.

17. Naves M, Díaz-López JB, Gómez C, Rodríguez-Rebollar A, RodríguezGarcía M, Cannata-Andía JB: The effect of vertebral fracture as a risk factor for osteoporotic fracture and mortality in a Spanish population. Osteoporos Int 2003, 14(6):520-524.

18. Briggs A, Greig A, Wark J: The vertebral fracture cascade in osteoporosis: a review of aetiopathogenesis. Osteoporos Int 2007, 18(5):575-584.

19. Melton L: Vertebral fractures predict subsequent fractures. Osteoporos Int 1999, 10:214-221.

20. Middleton E, Gardiner E, Steel S: Which women should be selected for vertebral fracture assessment? Comparing different methods of targeting VFA. Calcif Tissue Int 2009, 85(3):203-210.

21. Puisto $V$, Heliövaara M, Impivaara $O$, Jalanko T, Kröger $H$, Knekt $P$, Aromaa $A$, Rissanen $\mathrm{H}$, Helenius I: Severity of vertebral fracture and risk of hip fracture: a nested case-control study. Osteoporos Int 2011, 22(1):63-68.

22. Burger H, Van Daele PLA, Grashuis K, Hofman A, Grobbee DE, Schütte HE, Birkenhäger JC, Pols HAP: Vertebral deformities and functional impairment in men and women. J Bone Miner Res 1997, 12(1):152-157.

23. Melton $L$, Wenger $D$, Atkinson $E$, Achenbach $S$, Berquist $T$, Riggs $B$, Jiang $G$, Eastell R: Influence of baseline deformity definition on subsequent vertebral fracture risk in postmenopausal women. Osteoporos Int 2006, 17(7):978-985.

24. Pasco J, Henry M, Korn S, Nicholson G, Kotowicz M: Morphometric vertebral fractures of the lower thoracic and lumbar spine, physical function and quality of life in men. Osteoporos Int 2009, 20(5):787-792.

25. Ho-Pham LT, Nguyen ND, Vu BQ, Pham HN, Nguyen TV: Prevalence and risk factors of radiographic vertebral fracture in postmenopausal Vietnamese women. Bone 2009, 45(2):213-217.

26. Clark P, Cons-Molina F, Deleze M, Talavera J, Palermo L, Cummings S: The prevalence of radiographic vertebral fractures in Mexican men. Osteoporos Int 2010, 21(9):1523-1528. 
27. van Schoor N, Ewing S, O'Neill T, Lunt M, Smit J, Lips P: Impact of prevalent and incident vertebral fractures on utility: results from a patient-based and a population-based sample. Qual Life Res 2008, 17(1):159-167.

28. Grazio S: Prevalence of vertebral fractures in an urban population in Croatia aged 50 years and older. Wien Klin Wochenschr 2005, 117:(1-2):4247.

29. Cauley JA, Palermo L, Vogt M, Ensrud KE, Ewing S, Hochberg M, Nevitt MC, Black DM: Prevalent vertebral fractures in black women and white women. J Bone Miner Res 2008, 23(9):1458-1467.

30. Jones G: Prevalent vertebral deformities: relationship to bone mineral density and spinal osteophytosis in elderly men and women. Osteoporos Int 1996, 6(3):233-239.

31. Gallacher S, Gallagher A, McQuillian C, Mitchell P, Dixon T: The prevalence of vertebral fracture amongst patients presenting with non-vertebral fractures. Osteoporos Int 2007, 18(2):185-192.

32. Vokes TJ, Gillen DL, Pham AT, Lovett JM: Risk factors for prevalent vertebral fractures in black and white female densitometry patients. $J$ Clin Densitom 2007, 10(1):1-9.

33. Lansdown D, Bennet B, Thiel S, Ahmed O, Dixon L, Vokes T: Prevalence of vertebral fractures on chest radiographs of elderly African American and Caucasian women. Osteoporos Int 2011, 22(8):2365-2371.

34. Rostom S, Allali F, Bennani L, Abouqal R, Hajjaj-Hassouni N: The prevalence of vertebral fractures and health-related quality of life in postmenopausal women. Rheumatol Int/ 2011, (DOI 10.1007/s00296-0101734-5).

35. Lofthus CM, Osnes EK, Falch JA, Kaastad TS, Kristiansen IS, Nordsletten L Stensvold I, Meyer HE: Epidemiology of hip fractures in Oslo, Norway. Bone 2001, 29(5):413-418.

36. Lofthus C, Frihagen F, Meyer H, Nordsletten L, Melhuus K, Falch J: Epidemiology of distal forearm fractures in Oslo, Norway. Osteoporos Int 2008, 19(6):781-786

37. Jacobsen BK, Eggen AE, Mathiesen EB, Wilsgaard T, Njølstad I: Cohort profile: the Tromsø study. Int J Epidemiol 2011, (DOI 10.1093/ije/dyr049).

38. Jacobsen BK, Njolstad I, Thune I, Wilsgaard T, Lochen M-L, Schirmer H: Increase in weight in all birth cohorts in a general population: the Tromso study, 1974-1994. Arch Intern Med 2001, 161(3):466-472.

39. Diacinti D, Guglielmi G: Vertebral morphometry. Radiol Clin North Am 2010, 48(3):561-575.

40. El Maghraoui A, Roux C: DXA scanning in clinical practice. QJM 2008, 101(8):605-617.

41. Grigoryan M, Guermazi A, Roemer F, Delmas P, Genant H: Recognizing and reporting osteoporotic vertebral fractures. Eur Spine J 2003, 12(0): S104-S112

42. Ensrud KE, Schousboe JT: Vertebral fractures. N Engl J Med 2011, 364(17):1634-1642

43. Sanfélix-Genovés J, Reig-Molla B, Sanfélix-Gimeno G, Peiró S, GraellsFerrer M, Vega-Martínez M, Giner V: The population-based prevalence of osteoporotic vertebral fracture and densitometric osteoporosis in postmenopausal women over 50 in Valencia, Spain (the FRAVO Study). Bone 2010, 47(3):610-616.

44. Omsland TK, Emaus N, Gjesdal CG, Falch JA, Tell GS, Forsen L, Berntsen GK, Meyer HE: In vivo and in vitro comparison of densitometers in the NOREPOS study. J Clin Densitom 2008, 11(2):276-282.

45. O'Neill TW, Felsenberg D, Varlow J, Cooper C, Kanis JA, Silman AJ: The prevalence of vertebral deformity in European men and women: the European vertebral osteoporosis study. J Bone Miner Res 1996, 11(7):1010-1018

46. Johnell O, Kanis J: Epidemiology of osteoporotic fractures. Osteoporos Int 2005, 16(0):S3-S7.

47. Emaus $\mathrm{N}$, Olsen $\mathrm{L}$, Ahmed L, Balteskard L, Jacobsen B, Magnus T, Ytterstad B: Hip fractures in a city in Northern Norway over 15 years: time trends, seasonal variation and mortality. Osteoporos Int 2011, 22(10):2603-2610.

48. Cummings SR, Melton LJ: Epidemiology and outcomes of osteoporotic fractures. The Lancet 2002, 359(9319):1761-1767.

\section{Pre-publication history}

The pre-publication history for this paper can be accessed here:

http://www.biomedcentral.com/1471-2474/13/3/prepub doi:10.1186/1471-2474-13-3

Cite this article as: Waterloo et al:: Prevalence of vertebral fractures in women and men in the population-based Tromsø Study. BMC

Musculoskeletal Disorders 2012 13:3.

\section{Submit your next manuscript to BioMed Central and take full advantage of:}

- Convenient online submission

- Thorough peer review

- No space constraints or color figure charges

- Immediate publication on acceptance

- Inclusion in PubMed, CAS, Scopus and Google Scholar

- Research which is freely available for redistribution

Submit your manuscript a www.biomedcentral.com/submit
C Biomed Central 